\title{
The Role of Blocked Gratitude in Non-Voluntary Tipping
}

Ismail Karabas

Murray State University, ikarabas@murraystate.edu

Jeff Joireman

Washington State University

Follow this and additional works at: https://digitalcommons.murraystate.edu/faculty

Part of the Hospitality Administration and Management Commons

\section{Recommended Citation}

This is an Accepted Manuscript of an article published by Emerald Insight in Journal of Services Marketing on July 31, 2020, available online: https://doi.org/10.1108/JSM-03-2020-0082

This Peer Reviewed/Refereed Publication is brought to you for free and open access by Murray State's Digital Commons. It has been accepted for inclusion in Faculty \& Staff Research and Creative Activity by an authorized administrator of Murray State's Digital Commons. For more information, please contact msu.digitalcommons@murraystate.edu. 


\title{
The Role of Blocked Gratitude in Non-Voluntary Tipping
}

\begin{abstract}
Purpose: Non-voluntary tipping (e.g., automatic gratuity) has received growing attention in the service industry. Existing research suggests customers respond unfavorably to non-voluntary tipping, yet little research has examined why. The current studies address this question, with particular interest in response to non-voluntary tipping under high quality service.

Design/methodology/approach: Two scenario-based experiments tested the proposed hypotheses in between-participants design using ANOVA, hierarchical regression, and PROCESS.

Findings: Study 1 showed that non-voluntary tipping resulted in higher negative emotions, which led to lower return intentions. Surprisingly, the negative effect of non-voluntary tipping was as strong (or stronger) under high (vs. low) quality service. To understand this counterintuitive effect, study 2 developed and tested two competing process models (i.e., blocked vengeance vs. blocked gratitude). Supporting the blocked gratitude model, results revealed that non-voluntary tipping hinders customers' ability to reward service employees, undermining positive emotions, and lowering return intentions.

Research limitations/implications: Current work was conducted in two settings using two scenario-based experiments. Hence, additional settings with non-scenario-based studies are encouraged.

Practical implications: The present work cautions managers considering a move to nonvoluntary tipping to be aware of its negative effects, especially when the service quality is high. The blocked gratitude model suggests that managers should clarify methods available for customers who wish to reward good service.

Originality/value: This paper is the first to examine customer response to non-voluntary tipping under different levels of service quality, and the underlying emotional mechanisms.
\end{abstract}

Keywords: service inclusive pricing; non-voluntary tipping policy; mandatory gratuity; service charge; emotions; blocked vengeance; blocked gratitude; service quality 


\section{The Role of Blocked Gratitude in Non-Voluntary Tipping}

\section{Introduction}

Customers in North America spend an estimated $\$ 66$ billion a year on tips, ${ }^{1}$ primarily to reward or punish service employees (e.g., Kwortnik et al., 2009), follow social norms (e.g., Lynn et al., 1993), or communicate their dissatisfaction and retaliate when they prefer to avoid lodging direct complaints (Voorhees et al., 2006). In return, tipping increases customer service quality through heightened employee motivation (Kwortnik et al., 2009) and enhances employee retention rate (Lynn et al., 2011).

Despite the many important functions of voluntary tipping, some establishments are switching to non-voluntary tipping systems which increase prices to account for service charges or automatically add tips to the bill (Kwortnik et al., 2009; Lynn and Wang, 2013; Moskin, 2016; Wee, 2016). An American Express survey of 503 U.S. restaurants showed that $18 \%$ have adopted non-voluntary tipping while an additional $29 \%$ are expected to soon follow suit (see Lynn and Brewster, 2018; Wee, 2016). Managers indicate that non-voluntary tipping systems aim to provide equal pay among employees with different duties (e.g., Chicago Tribune, 2016). While admirable, non-voluntary tipping systems result in several negative customer reactions. For example, customers are less likely to patronize an establishment with non-voluntary tipping because they perceive non-voluntary tipping policies as less fair and more expensive than voluntary tipping (Lynn and Wang, 2013). In addition, non-voluntary tipping leads to lower customer satisfaction (Lynn and Kwortnik, 2015) and perceived service quality (Kwortnik et al., 2009), unless it occurs in a context where tipping is rare such as the cruise industry (Lynn and

\footnotetext{
${ }^{1}$ Based on restaurant industry food and drink sales projections for 2019, released annually by the National Restaurant Association (NRA). The calculations of Azar (2011) was taken as the basis, minus the lodging places since they were not specified in the 2019 report of the NRA. We multiplied the sales in full-service restaurants - $\$ 285.3$ billion; snack and nonalcoholic beverage bars - $\$ 43.7$ billion; bars and taverns - $\$ 22$ billion by the average tip percentage Azar (2011) used, 18.8\% (\$351 billion * $18.8=\$ 65.99$ billion).
} 
Kwortnik, 2020). Finally, non-voluntary tipping decreases actual service quality because it reduces service employees' motivation to provide high quality service (Kwortnik et al., 2009). While these studies offer insight, much remains to be learned about responses to non-voluntary tipping systems. Accordingly, the present research aims to better understand responses to voluntary versus non-voluntary tipping systems. ${ }^{2}$

Consistent with existing research (e.g., Lynn and Brewster, 2018; Lynn and Wang, 2013), and drawing on self-determination theory (Ryan and Deci, 2000), we expect customers will evidence less favorable reactions toward non-voluntary (vs. voluntary) tipping systems (e.g., return intentions), and report two studies examining why this occurs. In study 1, we propose that non-voluntary systems result in negative emotions, translating into lower return intentions. Complementing our mediation model, we test a buffering hypothesis positing that non-voluntary tipping systems should be less problematic under high (vs. low) quality service. In study 2, we develop and test a more comprehensive framework to account for our counterintuitive finding (in study 1) that negative reactions to non-voluntary tipping systems are as strong (or stronger) under high and low service quality. As we explain following study 1 , the expanded framework incorporates two competing models to account for the negative effect of non-voluntary tipping systems. The blocked vengeance model assumes that non-voluntary tipping systems interfere with the ability to punish a server, increasing negative emotions and reducing future return

\footnotetext{
${ }^{2}$ Respondents in a pilot study $(N=188$, MTurk) rated their experience with, attitudes towards, and preference between voluntary tipping, built-in gratuity (where a tip is built into menu prices) and automatic gratuity (where a tip is automatically applied at time of payment). Most respondents had experienced voluntary tipping (90.7\%), and a notable proportion had encountered automatic (44.1\%) and built-in gratuity $(31.4 \%)$. Consistent with prior research, respondents had more favorable attitudes (7-point scale) toward voluntary $(M=6.00)$ than toward built-in $(M=$ $4.85)$ or automatic gratuity $(M=3.73)$ (all Tukey tests, $p<.05)$. Similarly, respondents were significantly $(p<.001)$ more likely to select voluntary $(67.8 \%)$ over automatic $(19.5 \%)$ and built-in gratuity $(12.7 \%)$, with the latter not significantly different. In sum, results show that non-voluntary tipping systems are reasonably common in the marketplace and reinforce prior research suggesting customers respond less favorably towards non-voluntary tipping systems. Readers interested in a more detailed summary may contact the first author.
} 
intentions. The blocked gratitude model proposes that non-voluntary tipping systems impede the ability to reward the server, reducing positive emotions and return intentions.

The present work offers three contributions. First, by testing the blocked vengeance vs. blocked gratitude models, we delve deeper into how customers respond to non-voluntary tipping systems. Despite growing research indicating that customers respond negatively to non-voluntary tipping systems, little research examines why this occurs, leaving gaps in understanding the processes underlying these effects. Second, by demonstrating how non-voluntary tipping systems undermine reward motives and positive emotions, we highlight an underappreciated drawback to these systems, namely that they interfere with the customer's positive experience. This complements and extends prior research emphasizing how non-voluntary tipping systems result in negative perceptions such as increased cost, reduced service quality, and a lack of fairness. Lastly, we examine service quality as a moderator of the effects of non-voluntary tipping. While research shows that non-voluntary tipping systems decrease perceived and actual service quality (Kwortnik et al., 2009), customers' responses to non-voluntary tipping systems across different levels of service quality is absent. This is critical because customers' response to non-voluntary tipping may depend on the quality of service offered.

\section{Empirical review and theoretical development}

\subsection{Voluntary and non-voluntary tipping}

In the United States, voluntary tipping is a part of the traditional customer service experience, and most customers abide by the norm of voluntary payments to service employees (Azar, 2004). Customers tip a variety of different types of employees including bartenders, concierges, bellhops, hairstylists, parking valets, porters, taxi drivers, tour guides, and servers (Star, 1988). Customers may tip to show their gratitude or decide to not tip or to give a lower tip 
to indicate their dissatisfaction with the service (Voorhees et al., 2006). Research suggests that customers are content with voluntary tipping systems (Lynn and Withiam, 2008). However, evidence indicates that some service establishments, such as restaurants, are switching their voluntary tipping system to other systems that automatically build in a certain percentage of tip to the total charge. The general purpose of moving away from the traditional (voluntary) tipping system is to create equality between servers and other staff, who usually do not get tips, a system which tends to create inequity despite equal efforts. Although the removal of voluntary tipping holds good intentions, there is potential for negative customer reactions.

A number of studies offer initial evidence for the ways customers react to voluntary vs. non-voluntary tipping systems. For example, in the cruise ship industry, customers rated their experience more positively under voluntary tipping than under non-voluntary tipping systems (Lynn and Kwortnik, 2015). Moreover, in a survey by Wildes et al., (1998), 95\% of customers said they prefer voluntary tipping over service charges. Customers also report being less likely to patronize a restaurant when the restaurant has built-in gratuity (a percentage tip is built into menu prices) or automatic gratuity (a percentage tip is automatically added to the bill) compared to voluntary tipping (Lynn and Wang, 2013). And, relative to restaurants with voluntary tipping, customers perceive restaurants with non-voluntary tipping systems as more expensive, view the tipping system as less fair, and expect lower quality service (Lynn and Wang, 2013). A notable point is that existing studies did not focus on when customers learn about the non-voluntary tipping at an establishment (e.g., on the menu, on the check). Despite the potential difference in customer response, time of learning has either not been a part of the study (Lynn and Kwortnik, 2015, 2020) or participants were notified prior to dining (Lynn and Wang, 2013). 


\subsection{Perceived control and negative emotions}

The preceding literature suggests that customers prefer voluntary tipping systems and are more satisfied with the service when tipping is voluntary (vs. mandatory). Why this occurs is not as well understood. One possibility is that non-voluntary tipping systems undermine perceived control, leading to negative emotions. Voluntary tipping, for example, "puts [customers] in complete control of the services; allowing them to determine the value of the services they receive and to compensate accordingly" (Lynn and Wang, 2013, p. 64). This perceived control, in turn, has several benefits. For example, research shows that allowing customers to choose from a set of recovery options increases their overall satisfaction because of heightened sense of control (Chang, 2006). Customers who have more control over a service outcome are also less likely to blame a failure on a service provider (Van Raaij and Pruyn, 1998).

Non-voluntary tipping, on the other hand, can undermine perceived control (autonomy), one of the three needs within Ryan and Deci's (2000) self-determination theory (i.e., autonomy, competence, relatedness). According to self-determination theory (SDT), the satisfaction of three basic needs - autonomy, competence, and relatedness - is at the core of psychological well-being (Gagné and Deci, 2005; Ryan and Deci, 2000). One of these needs, autonomy, is especially likely to be threatened under non-voluntary tipping systems. Autonomy is the degree to which people have control over their choices (Deci and Ryan, 2000). When people have a sense of autonomy over their outcomes, they are more likely to engage in the behavior and be satisfied with the consequences. For example, consumers who are autonomously motivated are more likely to save household energy (Webb et al., 2013), lose weight (Williams et al., 1996), and donate to charity (Mulder and Joireman, 2016). Overall, research on SDT suggests that consumers value being in control of their decisions, are motivated toward conditions that will allow them satisfy their needs, and may react negatively when they sense a threat to their needs, 
potentially leading to emotions such as anxiety, grief, hostility, or anger (Ryan and Deci, 2000). For example, a lack of obvious alternative options to choose from can lead to negative emotions because customers enjoy the ability to affect the outcomes of their encounters (Bitner, 1992; Hui and Bateson, 1991). This is important because negative emotions such as anger predict costly consequences for firms including dissatisfaction (Bitner et al., 1990), desire for revenge (Joireman et al., 2013), and negative word of mouth (Bechwati and Morrin, 2003).

In sum, voluntary tipping has historically been an inherent part of customers' service experience which conveys a degree of autonomy (or what we will call control), with the freedom to decide the percentage a customer wishes to tip. In contrast, customers may perceive a nonvoluntary tipping system as an indicator of the establishment refusing to allow customers have complete control over their service experience, leading to negative emotional responses. Based on this reasoning, we advance the following hypotheses:

H1: Relative to voluntary tipping systems, non-voluntary tipping systems will lead to higher negative emotions $\left(\mathrm{H}_{1 \mathrm{a}}\right)$ and lower return intentions $\left(\mathrm{H}_{1 \mathrm{~b}}\right)$.

H2: Negative emotions will mediate the effect of tipping systems on return intentions. In the next section, we discuss service quality as a moderator of the anticipated effect of non-voluntary tipping systems just advanced. With its rich history in the service literature, service quality is an important determinant of customer service experience. As we explain, we reason that the hypothesized effects will be minimized when service quality is high (vs. low).

\subsection{Service quality, service failures, and tipping}

Customers judge service quality by comparing their perceived to their expected outcomes (Parasuraman et al., 1985). When outcomes meet or exceed expectations, customers are satisfied (Oliver, 1981). However, when outcomes drop below expectations, customers experience service 
failures (i.e., "any service-related mishaps or problems (real and/or perceived) that occur during consumer's experience with a firm"; Maxham, 2001, p. 11). Service failures (and failed recoveries) lead to perceived injustice (Goodwin and Ross, 1992), perceived negative motives (Joireman et al., 2013), desire for revenge (Karabas et al., 2019), anger (McColl-Kennedy et al., 2009; McColl-Kennedy et al., 2011), dissatisfaction (Maxham and Netemeyer, 2002;

McCollough et al., 2000), negative word of mouth (Blodgett et al., 1997), switching (Bechwati and Morrin, 2003), and sabotage (Kähr et al., 2016). Research indicates such retaliatory behaviors aim to get even with the employees and the firm (Bechwati and Morrin, 2003).

One retaliatory behavior, central to the current work, is reducing one's tip (Karabas et al., 2019; Voorhees et al., 2006). Research shows that service quality evaluations are a determinant of tipping (Lynn et al., 1993; Lynn and McCall, 2000), indicating that customers change the amount of tip they give as a function of the service quality they receive. This raises an interesting question: Namely, if customers use tipping as one means of getting revenge for low quality service, how might a non-voluntary tipping system influence customer behavioral intentions when the service quality is low and customers cannot retaliate by changing their tip?

In the present work, we expect that non-voluntary tipping will be more problematic to customers when the service quality is low compared to high. Receiving low quality service is unjust and customers seek for avenues to ensure their outcomes are fair (Grégoire and Fisher, 2008). When faced with low quality service, a non-voluntary tipping system removes tipping as an avenue for customers to "even the scales." As a result, taking away the ability to tip under low quality service should lead to unfavorable responses (e.g., heightened negative emotions).

In contrast, when service quality is high, customers may accept mandatory tips being included since tipping is a norm and expected, especially in response to good service. Although 
people likely prefer having the ability to determine their tip, they may not be as concerned about a non-voluntary tipping system since the service was good and they would likely have tipped anyway. Taken together, this line of reasoning would lead to an interaction between tipping systems and service quality, whereby the negative effects of non-voluntary tipping systems are diminished under high quality service. Thus, we advance the following hypothesis:

H3: Service quality will moderate the effect of tipping systems on negative emotions and return intentions, such that the negative effect of non-voluntary tipping systems will be buffered under high quality service.

\subsection{Overview of studies}

Next, we report two studies aimed at understanding customer response to non-voluntary tipping systems. Study 1 tests $\mathrm{H} 1-\mathrm{H} 3$, while study 2 tests an expanded model articulating why customers respond negatively to non-voluntary tipping when service quality is high.

\section{Study 1}

\subsection{Participants, design and procedures}

Participants from Amazon's MTurk $(N=200 ; 49.5 \%$ female; median age $=32.5 ; 70 \%$ Caucasian) read one of the four scenarios in a 2 (tipping system: voluntary tipping vs. automatic gratuity) x 2 (service quality: low vs. high) between-participants design. ${ }^{3}$ Participants imagined eating dinner out with friends (Appendix A). After arriving at the restaurant, participants ordered. In the high quality service, participants imagined they enjoyed their soup. In the low quality service, participants imagined receiving the wrong soup and asked for a replacement. The

\footnotetext{
${ }^{3}$ While some have questioned the use of MTurk, studies show that MTurk is commonly used (e.g., Karabas et al., 2020; Newton et al., 2018; Okan and Elmadag, 2020) because it provides demographically diverse, cost effective, and quality data (Berinski et al., 2012; Buhrmester et al., 2011; Kees et al., 2017; Paolacci and Chandler, 2014). We believe the present studies yield reliable findings given that we excluded previous participants in our studies each time we conducted a new study, our samples were fairly representative, manipulation checks showed our scenarios were interpreted as intended, our measures were reliable, and our findings replicated across numerous studies.
} 
server brought the correct soup but it took a while and the server treated them rudely. In both conditions, participants imagined paying after they were done eating. Next, participants read one of two scenarios with the tipping system manipulation (voluntary tipping vs. automatic gratuity), imagined making their payment, and completed the outcome measures.

\subsection{Measures}

Participants completed measures of return intentions ("How likely is it that you would return to this establishment again in the future?" $1=$ not at all likely, 7 = very likely; adapted from Boulding et al., 1993). As a check on the tipping system manipulation, participants completed a two-item perceived control scale $(\alpha=.73$; e.g., "Thinking about the tipping system in the scenario I just read, I feel that the tipping system is making me do things against my will," $1=$ strongly disagree, 7 = strongly agree; adapted from Mulder and Joireman, 2016, and Sheldon and Hilbert, 2012). Participants also completed a negative emotions scale (five items, $\alpha=.96$; e.g., "In the scenario I just read, I would feel outraged," $1=$ strongly disagree, 7 = strongly agree; adapted from Bougie et al., 2003) (all measures are shown in Appendix B).

As a check on the service quality manipulation, participants completed a three-item measure of perceived service quality $(\alpha=.96$; e.g., "The service here suited my needs," $1=$ strongly disagree, 7 = strongly agree; adapted from Grace and O'Cass, 2004). Lastly, participants rated the scenario's realism on a three-item scale $(\alpha=.92$; e.g., "The scenario is realistic," $1=$ strongly disagree, 7 = strongly agree; adapted from Wirtz et al., 2013).

\subsection{Results}

\subsubsection{Manipulation checks and perceived realism}

In support of our tipping system manipulation, a 2 (tipping system: voluntary vs. automatic) x 2 (service quality: low vs. high) ANOVA on perceived control revealed a 
significant main effect of tipping system, $F(1,196)=194.78, p<.001, \eta^{2}=.498$, with participants in the automatic gratuity condition reporting significantly lower perceived control $(M=2.55, S D=1.32)$ than participants in the voluntary tipping condition $(M=5.19, S D=1.35)$. Neither the main effect of service quality nor the interaction were significant $(p$ 's $>.13)$. Supporting our service quality manipulation, a 2 (tipping system: voluntary vs. automatic) x 2 (service quality: low vs. high) ANOVA on perceived service quality yielded a significant main effect of service quality, $F(1,196)=262.67, p<.001, \eta^{2}=.573$, with the low and high quality conditions perceived as intended $\left(M_{\text {highquality }}=5.52, S D=1.11 \mathrm{vs.} M_{\text {lowquality }}=\right.$ $2.77, S D=1.37)$. Results also revealed a significant main effect of tipping system, $F(1,196)=$ 14.32, $p<.001, \eta^{2}=.068$; participants in the automatic gratuity condition reported significantly lower service quality evaluations $(M=3.89, S D=1.78)$ than participants in the voluntary tipping $(M=4.48, S D=1.89)$, a finding we consequently account for in our primary analyses.

Lastly, a 2 (tipping system: voluntary vs. automatic) x 2 (service quality: low vs. high) ANOVA on perceived realism revealed that voluntary gratuity was rated as more realistic than automatic gratuity, $F(1,196)=5.08, p<.05, \eta^{2}=.025$. Nevertheless, both gratuity conditions reported high levels of scenario realism $\left(M_{\text {voluntary }}=6.25, S D=.98, M_{\text {automatic }}=5.92, S D=1.07\right)$, with each mean significantly above the scale midpoint of $4(p<.001)$.

\subsubsection{Primary analyses}

To test $\mathrm{H} 1$ and $\mathrm{H} 3$, we conducted 2 (tipping system: voluntary tipping vs. automatic gratuity) x 2 (service quality: low vs. high) ANOVAs on negative emotions and return intentions. In line with H1, results revealed a significant main effects of tipping system on negative emotions, $F(1,196)=60.38, p<.001, \eta^{2}=.24$, and return intentions, $F(1,196)=39.89, p<$ $.001, \eta^{2}=.17$, with automatic gratuity leading to less favorable responses than voluntary tipping 
(Figure 1). Results also revealed a significant main effect of service quality on negative emotions, $F(1,196)=138.88, p<.001, \eta^{2}=.42$, and return intentions, $F(1,196)=131.27, p<$ $.001, \eta^{2}=.40$, with high service quality leading to more favorable responses (Figure 1). Lastly, results showed a significant interaction between tipping system and service quality on negative emotions, $F(1,196)=4.63, p<.05, \eta^{2}=.03$. However, counter to $\mathrm{H} 3$, the effect of tipping system on negative emotions was stronger under high quality than under low quality service, as can be seen in Figure 1 (Panel A). Similarly, the difference between voluntary and automatic tipping on return intentions was larger under high quality service than low quality service (Figure 1, Panel B), though the interaction was not significant, $F(1,196)=2.54, p=.11, \eta^{2}=.03$.

[Insert Figure 1 about here]

\subsubsection{Process-related analyses}

Finally, using Hayes' (2013) PROCESS model 4, we tested the indirect effect of tipping system on return intentions through negative emotions (controlling for service quality).

Consistent with $\mathrm{H} 2$, the indirect effect was significant $\left(\mathrm{CI}_{.95}=-.8749,-.3255\right)$, as shown in

Figure 2. At the same time, the direct (residual) path from tipping system to return intentions remained significant, suggesting the presence of additional mediating mechanisms.

[Insert Figure 2 about here]

\subsection{Discussion}

\subsubsection{Summary of findings}

Study 1 revealed that customers report greater negative emotions and weaker return intentions under non-voluntary tipping systems, and the negative effect of non-voluntary tipping systems on return intentions is party explained by negative emotions, supporting H1 and H2. 
However, counter to H3, in study 1 - and two preliminary studies ${ }^{4}$ - the negative effect of nonvoluntary tipping was as strong or stronger under high (vs. low) quality service.

The strong and reliable negative impact of non-voluntary tipping under high quality service is intriguing for both practical and theoretical reasons. For example, because service at (U.S.) restaurants is normally rated highly (Azar, 2009), understanding the counterintuitive (negative) impact of non-voluntary tipping systems under high quality service would offer important managerial insights with wide applicability. Gaining insight into why non-voluntary tipping systems have a negative impact under service successes could also offer valuable theoretical insights by highlighting the role of positive motives and emotions that go beyond revenge and negative emotions, negatively-valenced constructs frequently used to understand responses to service failures (Voorhees et al., 2017). Thus, in study 2, we endeavor to understand why non-voluntary tipping systems activate less favorable responses under high quality service.

\subsubsection{Addressing limitations}

In so doing, study 2 addresses four limitations with our initial studies. First, while customers in the high quality condition rated service quality above the midpoint (5.5), getting one's correct order at a restaurant may not have represented service quality high enough to buffer against the negative effect of a non-voluntary tipping system. Thus, in order to provide a stronger test of the predicted buffering effect in $\mathrm{H} 3$, in study 2 , we focus on how customers respond to non-voluntary tipping under high (correct order) versus very high (excellent) quality service.

\footnotetext{
${ }^{4}$ Our two preliminary studies, which focused on voluntary vs. built-in gratuity systems, set in restaurant $(N=196)$ and hair salon contexts $(N=201)$, revealed results consistent with study 1 . Namely, negative emotions were significantly higher, and return intentions were significantly lower, when the establishment used a built-in (vs. a voluntary) tipping system, and these effects were as strong (restaurant) or stronger (hair salon) in the high service quality condition. In sum, data from three studies consistently failed to support the hypothesis that the negative impact of non-voluntary tipping systems would be buffered by high quality service. While the preliminary studies were informative, they focused on a less common type of non-voluntary tipping (built-in) and did not assess perceived control (an important check for our tipping system manipulation). As such, we do not discuss them in the main body of the paper. Readers interested in a summary of the preliminary studies may contact the first author.
} 
Second, in our initial studies, customers learned of the tipping system after the service had been rendered, which may have come as a surprise. Moreover, many restaurants announce their non-voluntary tipping system before the customer orders and is served (e.g., on the menu). Thus, in study 2, the tipping system is introduced before the service is provided.

Third, a sole focus on negative emotions as a mediator raises several concerns. First, as noted, negative emotions only partly explained the negative impact of non-voluntary tipping on return intentions, highlighting the existence of additional mediating mechanisms. Another concern is that heightened negative emotions may, upon closer inspection, be serving as a proxy for diminished positive emotions, obscuring insights into the precise emotion (or emotions) driving the effect. Relatedly, as we explain, assessing negative and positive emotions is essential to testing competing explanations for why customers respond negatively to non-voluntary tipping systems, namely the "blocked vengeance" vs. the "blocked gratitude" accounts.

Finally, our initial studies did not directly examine how (thwarted) abilities resulting from non-voluntary tipping systems - critical to the competing models - drive negative and positive emotions affecting return intentions. Thus, study 2 tests how non-voluntary tipping systems affect the perceived ability to punish and reward the server, abilities directly relevant to the competing "blocked vengeance" and "blocked gratitude" models to which we now turn.

\section{Blocked vengeance vs. blocked gratitude models}

As noted, our interaction hypothesis proposed that the negative effect of non-voluntary tipping systems would be buffered (weakened or eliminated) by high quality service. This hypothesis was based on the assumption that customers view non-voluntary tipping systems as a threat to their control, and under high quality service, customers would show little concern over reduced control, as there would be no need to punish a server for bad service. Surprisingly, our 
interaction hypothesis failed to receive support across three studies, as the negative impact of non-voluntary tipping systems was as strong or stronger under high quality service.

To understand why high quality service failed to buffer the negative effect of nonvoluntary tipping systems, it is necessary to recognize that tipping serves a wide range of motives. While lower tips can be used to express displeasure and punish a server (e.g., Karabas et al., 2019; Voorhees et al., 2006), many of the motives underlying tipping are positive (e.g., helping the server and/or expressing gratitude toward the server; Lynn, 2016). In theory, positive motives should be especially likely to motivate tipping under high quality service. Thus, modeling how positive motives are thwarted under non-voluntary tipping systems could significantly expand an understanding of our counterintuitive finding.

Toward that end, we explicate and test the "blocked vengeance" and "blocked gratitude" models (Figure 3). According to the blocked vengeance model, non-voluntary tipping systems interfere with the ability to punish a server which increases negative emotions and reduces return intentions. Our initial interaction hypothesis (H3) was based on this line of thinking. The blocked gratitude model proposes that non-voluntary tipping systems interfere with the ability to reward a server which reduces positive emotions and return intentions. Study 2 tested the relative ability of these competing models to explain negative reactions to non-voluntary tipping when service quality is high, which past research suggests is more the norm than the exception (Azar, 2009). [Insert Figure 3 about here]

\section{Study 2}

\subsection{Participants, design, and procedures}

Participants from Amazon's MTurk $(N=206 ; 39.8 \%$ female; median age $=34.0 ; 78 \%$ Caucasian) read one of four scenarios in a 2 (tipping system: voluntary tipping vs. automatic 
gratuity) x 2 (service quality: high vs. very high) between-participants design. As in study 1 , participants imagined they had gone out to eat dinner with friends (Appendix A). After arriving, being seated, and perusing the menu, participants read a notice on the menu describing the voluntary (or non-voluntary) tipping system. After ordering and receiving their soup, participants were randomly assigned to one of the two service quality conditions. Identical to study 1 , in the high quality service condition, participants imagined they enjoyed their soup. In the very high quality service condition, participants imaged they enjoyed their soup and (additionally) "thought the overall service was excellent." In both conditions, participants imagined proceeding to payment after they were done eating. Consistent with study 1, those in the voluntary condition imagined inserting a tip, signing the check, and leaving the restaurant. In the non-voluntary condition, participants read that "since the tip was automatically added to the bill, you just signed the check and left the restaurant." While the tipping system was mentioned again at the end of the scenario (to ensure a smooth narrative), as noted earlier, all participants learned of the tipping system before imagining their service. Following the scenario, participants completed the relevant manipulation checks and dependent variables.

\subsection{Measures}

After completing a one-item return intentions measure $(1=$ very unlikely, $7=$ very likely), participants rated the extent to which the tipping system they read about allowed them to reward the server (i.e., reward for good service, repay the server for his/her efforts; $\alpha=.80$; adapted from Lynn, 2016) and punish the server (i.e., punish bad service, get back at a server who treats me badly; $\alpha=.93)$. Next, participants completed the perceived control scale from study $1(\alpha=.54)$, and rated the extent to which they experienced a set of three positive emotions (i.e., happy, content, pleased; $\alpha=.92$; adapted from McNiel et al., 2010) and three negative 
emotions (i.e., angry, resentful, annoyed; $\alpha=.95)(1=$ strongly disagree, $7=$ strongly agree).

Lastly, participants rated the extent to which the establishment provided quality service and the scenario was realistic $(1=$ strongly disagree, $7=$ strongly agree $) .{ }^{5}$

\subsection{Results}

\subsubsection{Manipulation checks and perceived realism}

In support of our tipping system manipulation, a 2 (tipping system: voluntary vs. automatic) x 2 (service quality: high vs. very high) ANOVA on perceived control revealed a significant main effect of tipping system, $F(1,202)=166.78, p<.001, \eta^{2}=.452$, with participants in the automatic gratuity condition reporting significantly lower perceived control $(M=3.12, S D=1.19)$ than participants in the voluntary tipping $(M=5.52, S D=1.39)$. Neither the main effect of service quality nor the interaction were significant (p-values > .66). ${ }^{6}$

Supporting our service quality manipulation, a 2 (tipping system: voluntary vs. automatic) x 2 (service quality: high vs. very high) ANOVA indicated that the very high quality condition led to higher perceived service quality $(M=5.86, S D=0.95)$ than the high quality condition $\left(M_{\text {lowquality }}=5.63, S D=0.98\right)$, though the main effect was marginally significant, $F(1$, 202) $=3.18, p=.076, \eta^{2}=.015$. Consistent with study 1 , results also revealed a significant main effect of tipping system, $F(1,202)=20.39, p<.001, \eta^{2}=.092$, with participants in the automatic gratuity condition reporting significantly lower service quality evaluations $(M=5.46, S D=0.99)$ than participants in the voluntary tipping condition $(M=6.04, S D=0.86)$.

\footnotetext{
${ }^{5}$ In the interests of shortening the survey, in study 2, we reduced the length of the negative emotions scale (from 5 to 3 items) and utilized one-item (as opposed to three-item) measures for service quality and realism.

${ }^{6}$ Given that the reliability of the control scale in study 1 was somewhat low $(\alpha=.54)$, we also ran separate $2 \times 2$ ANOVAs on each control item individually. Results were identical to the two-item control scale, with a significant main effect for the tipping system $(p$ 's $<.001)$, increasing confidence in the overall two-item measure.
} 
Lastly, a 2 (tipping system: voluntary vs. automatic) x 2 (service quality: high vs. very high) ANOVA on perceived realism revealed that voluntary gratuity was rated as more realistic than automatic gratuity, $F(1,202)=17.62, p<.001, \eta^{2}=.08$. Nevertheless, both gratuity conditions reported high levels of scenario realism $\left(M_{\text {voluntary }}=6.22, S D=.96, M_{\text {automatic }}=5.63\right.$, $S D=1.13)$, with each mean significantly above the scale midpoint of $4(p<.001)$.

\subsubsection{Primary analyses}

We first conducted 2 (tipping system: voluntary tipping vs. automatic gratuity) x 2 (service quality: high vs. very high) ANOVAs on the five dependent measures (ability to punish, ability to reward, negative emotions, positive emotions, and return intentions). Results revealed a significant main effect of tipping system on each outcome measure: relative to voluntary tipping, automatic tipping led to significantly lower return intentions $\left(M_{\text {automatic }}=5.11, S D=1.37\right.$ vs. $\left.M_{\text {voluntary }}=5.79, S D=1.00 ; F(1,202)=16.87, p<.001, \eta^{2}=.08\right)$, ability to reward $\left(M_{\text {automatic }}=\right.$ 4.07, $S D=1.55$ vs. $\left.M_{\text {voluntary }}=5.85, S D=1.01 ; F(1,202)=94.18, p<.001, \eta^{2}=.318\right)$, ability to punish $\left(M_{\text {automatic }}=2.86, S D=1.80\right.$ vs. $M_{\text {voluntary }}=4.22, S D=1.76 ; F(1,202)=29.73, p<.001$, $\left.\eta^{2}=.128\right)$, and positive emotions $\left(M_{\text {automatic }}=4.62, S D=1.46\right.$ vs. $M_{\text {voluntary }}=5.54, S D=1.02$; $\left.F(1,202)=29.29, p<.001, \eta^{2}=.119\right)$, and significantly higher negative emotions $\left(M_{\text {automatic }}=\right.$ $3.39, S D=1.82$ vs. $\left.M_{\text {voluntary }}=2.28, S D=1.71 ; F(1,202)=20.70, p<.001, \eta^{2}=.093\right)$. Results also revealed a significant main effect of service quality on return intentions, with those in the very high quality condition more likely to return $\left(M_{\text {very } h i g h}=5.63, S D=1.21\right.$ vs. $M_{\text {high }}=5.25, S D$ $\left.=1.26 ; F(1,202)=5.58, p<.05, \eta^{2}=.027\right)$. The two-way interaction was not significant on any of the outcome variables ( $\mathrm{p}$-values $>.34)$. 


\subsubsection{Process-related analyses: blocked vengeance vs. blocked gratitude models}

Next, to gain initial insight into the relative strengths of the blocked vengeance vs. blocked gratitude models, we next conducted a three-step hierarchical regression, entering tipping system (and service quality as a control variable) on step 1, ability to punish and reward on step 2, and negative and positive emotions on step 3. Table I presents the correlation matrix while Table II summarizes the hierarchical regression results. As can be seen, the overall pattern clearly supports the blocked gratitude model. For example, on step 2 , tipping system became non-significant, while ability to reward (and not ability to punish) was a significant predictor of return intentions. Moreover, on step 3, the relationship between ability to reward and return intentions became less significant while positive emotions (and not negative emotions) predicted return intentions. These results indicate that when the abilities and emotions relevant to the blocked vengeance and blocked gratitude models are allowed to compete, the predictors within the blocked gratitude model best explain responses to non-voluntary tipping.

\section{[Insert Tables I and II about here]}

Complementing and extending the regression, we used Hayes (2018) PROCESS (custom model 82) to simultaneously test the indirect effects proposed in the competing models, with service quality included as a control variable. Coefficients for the models are shown in Figure 4. Whereas the indirect effect specified by the blocked vengeance model (non-voluntary tipping system $\rightarrow$ ability to punish $\rightarrow$ negative emotions $\rightarrow$ return intentions) was not significant (CI.95 $=$ $-.0121, .0856$ ), the indirect effect specified by the blocked gratitude model (non-voluntary

tipping system $\rightarrow$ ability to reward $\rightarrow$ positive emotions $\rightarrow$ return intentions) was significant $(\mathrm{CI} .95=-.7738,-.2607)$, offering additional and clear support for the blocked gratitude model. 


\subsection{Discussion}

With a focus on high quality service, study 2 yielded two key findings. First, relative to voluntary tipping, an automatic tipping system led to reduced ability to reward and punish the server, weaker positive emotions, lower return intentions, and heightened negative emotions. Second, process-related findings clearly supported the blocked gratitude model. ${ }^{7}$ These results complement and extend our initial findings in study 1, offering clarity on why non-voluntary tipping reduces return intentions when service quality is high. In sum, results suggest that when service quality is high, a non-voluntary tipping system interferes with the ability to reward the server for high quality service, in turn, undermining positive emotions and return intentions.

\section{General discussion}

Providing adequate compensation for service employees and redressing the pay gap between tipped and untipped employees are significant challenges for managers (Galarza, 2017). As one potential solution, service establishments may consider adopting a non-voluntary tipping system (e.g., increasing menu prices, adding automatic service charges to the check), a notable deviation from traditional voluntary tipping. While existing literature shows that customers respond unfavorably toward non-voluntary tipping (Kwortnik et al., 2009; Lynn and Brewster 2018; Lynn and Kwortnik, 2015; Lynn and Wang, 2013), insights into the underlying mechanisms, and conditions under which non-voluntary tipping may be more or less problematic, remain underexplored. In addressing these gaps, the current work yielded three key findings. First, non-voluntary tipping increased negative emotions, which resulted in lower return intentions. Second, counter to our initial reasoning, the negative effect of non-voluntary tipping

\footnotetext{
${ }^{7}$ Counter to our model, ability to punish was positively related with negative emotions. It is possible that when service quality is high or very high, the perceived ability to punish may result in negative consequences within customers, for example, through a simple associative network linking ability to punish with negative emotions.
} 
on negative emotions and return intentions was as strong or stronger when service quality was high (vs. when it was low). Third, non-voluntary tipping hindered customers' ability to reward high quality service, diminishing positive emotions and return intentions.

One might assume that the negative customer response to non-voluntary tipping is due to non-voluntary tipping systems adding more on customers' bill than customers' typical tip. To investigate this possibility, we ran ancillary analyses comparing customers' self-reported usual tip percentages (i.e., what percentage tip do you usually leave at a restaurant?) to customers' assumptions on the percentage of tip automatic gratuity adds on their bill (i.e., what percentage of service charges do you think automatic gratuity adds?). Results of paired samples t-tests showed that customers either tip more than they assume automatic gratuity systems add (study 1: $M_{\text {usualtip }}=16.92, S D=4.41$ vs. $\left.M_{\text {automatic }}=14.26, S D=5.36 ; t(199)=6.68, p<.001\right)$ or the same as they expect automatic gratuity systems add (study $2: M_{\text {usualtip }}=15.93, S D=5.23$ vs. $M_{\text {automatic }}$ $=15.48, S D=4.84 ; t(205)=1.50, p=.14)$. These analyses further underscore the importance of blocked gratitude (vs. blocked vengeance) as the mechanism explaining negative customer responses to non-voluntary tipping (under high quality service).

\subsection{Research contributions}

The current work offers three contributions to the literature on customer response to nonvoluntary tipping. First, we identify theoretically-insightful and practically-valuable mechanisms that explain why customers respond negatively to non-voluntary tipping. Some existing research sheds light on the negative effect of non-voluntary tipping systems on outcomes such as lower patronage, and mediators such as perceived unfairness and cost associated with non-voluntary tipping (Lynn and Wang, 2013). To our knowledge, however, there is no research that focuses on understanding customers' emotional response to non-voluntary tipping as underlying 
mechanisms, or research explaining why customers might experience certain emotions in response to different tipping systems. Emotions are critical in service encounters due to their strong connection with behavioral intentions (e.g., Banik et al., 2019; Kim and Baker, 2019; Liu et al., 2019; Sukhu et al., 2019). Negative emotions (e.g., anger, irritation, frustration,) can often activate negative actions (e.g., negative word of mouth, switching; Bechwati and Morrin, 2003; McColl-Kennedy and Sparks, 2003; Richins, 1997; Xu et al., 2019), while positive emotions (e.g., happiness) lead to positive outcomes (e.g. loyalty, positive word of mouth; Babin et al., 2005; Rychalski et al., 2010). By testing competing models incorporating negative and positive emotions (i.e., blocked vengeance vs. blocked gratitude), the present work contributes to the understanding of the role of emotion in customer response to non-voluntary tipping. Our work also underscores the role of thwarted abilities to punish and reward the server as predictors of those emotions. In sum, the present work advances prior literature by developing and testing an integrative process-focused framework involving dual thwarted ability-emotion pathways linking tipping systems with return intentions.

Second, and relatedly, the current work shows how non-voluntary tipping systems interfere with reward motives and positive emotions when service quality is high, a novel contribution beyond understanding the role of abilities and emotions more generally. Since most services are high in quality (Azar, 2009), it is critical to understand factors that may negatively affect the customer experience in such settings. To punish (Karabas et al., 2019; Voorhees et al., 2006) or to reward (Lynn 2009; 2016) are both possible tipping motivations, and non-voluntary tipping encumbers both. As noted, the present results showed that, under high quality service, non-voluntary tipping undermines the ability to reward one's server, which interferes with positive emotions, translating into reduced return intentions. To our knowledge, the present work 
is the first to demonstrate that non-voluntary tipping systems interfere with customers' desire to reward the service employees and tendency to experience positive emotions. Future research capitalizing on this shift in focus (from heightened negative experience to dampened positive experience) could yield additional insights into the drawbacks of non-voluntary tipping systems.

Lastly, the current studies explored the effects of non-voluntary tipping systems under low and high quality service. Existing research on non-voluntary tipping systems suggests that perceived and actual service quality decrease after the adoption of a non-voluntary tipping system (Kwortnik et al., 2009; Lynn and Brewster, 2018). That said, no prior work has examined responses to non-voluntary tipping systems under different levels of service quality. We hypothesized that negative response to a non-voluntary tipping system would be minimized when customers experience high quality service. However, counter to our expectations, the difference in customer response to voluntary and non-voluntary tipping systems was as large or larger under high quality. This counterintuitive yet reliable finding suggests that high quality service does not protect against the negative effects of non-voluntary tipping systems, which highlights important implications for managers, to which we now turn.

\subsection{Managerial implications}

Managers may assume that as long as service quality is high, patrons will accept nonvoluntary tipping systems, as there is no need to punish a server. However, counter to this intuitive reasoning, the present results show that when service quality is high, non-voluntary tipping systems undermine the ability to reward servers, dampening positive emotions, and undermining return intentions. These findings should sound a clarion call for managers to think carefully before implementing non-voluntary tipping systems. While managers offering high quality service may believe they are protected against the negative repercussions associated with 
non-voluntary tipping systems, our results suggest a non-voluntary tipping policy may undermine their efforts by counterintuitively interfering with the ability to reward servers and experience positive emotions. Indeed, the ability to punish and negative emotions may simply be a red herring when service quality is high, lulling managers into a false sense of security.

Given that non-voluntary tipping systems appear to interfere with the ability to reward servers and experience positive emotions, service establishments using non-voluntary tipping might consider implementing methods to alleviate the negative effect of non-voluntary tipping when service quality is high. For instance, a line on the check for additional tips, or a statement on the menu that customers can leave additional tips, or take some other action (e.g., voting for employee of the month), may grant customers an ability to reward good service, reducing the negative effect of non-voluntary tipping under high quality service. Content customers could also sign prefilled thank you cards on tables for servers to pick and distribute among the various positions (e.g., server, kitchen staff, bartender). This could provide an additional avenue for customers to reward good service, while also increasing motivation across all employees. The cards could also indicate that employees with most cards at the end of a certain period of time would receive a bonus payment. Furthermore, customers' ability to reward could also be restored by emphasizing that the automatic tip was still customers' contribution and not a default amount. A note on the bill emphasizing the automatic tip amount and thanking the customer for their tip may be a way to remind customers that they did, in a manner of speaking, rewarded their server.

Because non-voluntary tipping systems also appear to undermine perceived control, managers might take steps to heighten or restore customers' sense of losing control over tipping. For example, it is possible that an automatic gratuity may be presented as a default option, while 
still offering customers the final say in whether they use the default automatic tipping system, or a more standard voluntary tipping system.

In addition, the present studies provide practical insights toward the timing of informing customers about the non-voluntary tipping system. In study 1, participants learned about the nonvoluntary tipping system at the time of payment, while in study 2 participants learned about the tipping system prior to dining. Although not the focus of our work, it is possible that customers' service evaluations may be different based on when they learn that the tip would be automatically added to their bill. While learning at the time of payment may come as a surprise, learning before commitment to purchase the service (e.g., seeing it on the menu) may lead to a couple of possible effects. On the one hand, automatic tips may increase customers' expectations for the quality of service. On the other hand, customers would be prepared for the automatic tips and it would give them the option to not buy the service. To test these possible explanations, we merged the service quality evaluations in both studies from the non-voluntary tipping/high quality conditions $(N=105)$. Results of an independent samples t-test revealed a nonsignificant effect $(p=.57)$, suggesting that learning about the non-voluntary tipping on the menu or at the time of payment did not have an effect on service quality evaluations.

\subsection{Limitations and future research}

While the current research makes tangible contributions to theory and practice, several limitations should be considered. First, the studies relied on scenarios and self-report measures. Notably, scenarios have several benefits in this context. For example, scenarios allow for control over manipulated conditions while minimizing potential noise (Bitner, 1990). Scenarios also help role-play service failures and recoveries, which would be costly and time consuming to run as a real-life experiment (Smith et al., 1999). Even though scenarios are commonly used in the services literature (e.g., Bitner, 1990, Choi and Mattila, 2008; Karabas et al., 2019; Kwortnik et 
al., 2009; McCollough et al., 2000; Wan et al., 2011), field experiments could provide evidence for the robustness of the current findings in real settings with actual customer behavior. A second limitation of the current work is its generalizability. Even though we established our findings across two settings (restaurants, hair salons, as noted in Footnote 4), future work testing the replicability of the current findings across a wider range of settings (e.g., hotels, coffee shops) is encouraged. Indeed, some occupations are more likely to be tipped than others (Lynn, 2016), which may affect customers' response to non-voluntary tipping systems. Thus, future research should consider tip expectations as a potential moderator.

Beyond the avenues just noted, it would be valuable to examine what service providers can do to reduce negative response to non-voluntary tipping. Practices that can help restore perceived loss of control (e.g., customer feedback cards), or allow the customer to reward the server beyond an automatically-determined tip, could represent promising strategies for reducing negative responses to non-voluntary tipping. Anecdotally, some service establishments still leave a line for tips on the checks even though a certain percentage is already added automatically. In our studies, participants did not see a line on the check. Future research can test whether this would be a viable option for managers to allow customers to reward good service. Another construct that future research should consider is power. For example, tipping is more common in countries where people have a stronger need for power such that tipping provides customers with an opportunity to exert power over servers by choosing how much to tip (Lynn, 2000). In addition, recent research shows that anger and complaining are linked within high (but not low) power customers (Min et al., 2019). Given these findings, it would be interesting to explore whether response to non-voluntary tipping systems vary as a function of the customer's power. 


\section{Table I}

Correlation matrix (study 2)

$\begin{array}{lllllllll}\mathrm{M}(\mathrm{SD}) & 1 & 2 & 3 & 4 & 5 & 6 & 7\end{array}$

1. NV Tipping System N/A -

2. Service Quality N/A $.01 \quad-$

3. Ability to Punish $3.52(1.90) \quad-.36^{* *}-.02 \quad-$

4. Ability to Reward $4.93(1.59) \quad \begin{array}{llll}-.56^{* *} & .04 & .53^{* *} & -\end{array}$

5. Negative Emotions $2.85(1.85) \quad .30^{* *}-.10 \quad .25^{* *}-.25^{* *} \quad$ -

6. Positive Emotions $5.06(1.34) \quad-.34^{* *} \quad .10 \quad .36^{* *} \quad .65^{* *}-.37^{* *} \quad-$

7. Return Intentions $5.44(1.25) \quad-.27^{* *} \quad .16^{*} \quad .21^{* *} \quad .53^{* *}-.36^{* *} \quad .67^{* *} \quad-$

Note. $N=206 . * p<.05 ; * * p<.01$ (two-tailed). NV= non-voluntary. Tipping system:

voluntary (1) vs. automatic (2). Service quality: high (1) vs. very high (2). 


\section{Table II}

Hierarchical regression analysis testing abilities and emotions as mediators linking tipping systems with return intentions (study 2)

\begin{tabular}{lccccc}
\hline & B & SE & $\beta$ & $t$ & $p$ \\
Model 1 & & & & & \\
NV Tipping System & -0.68 & 0.17 & -0.27 & -4.10 & 0.001 \\
Service Quality & 0.40 & 0.17 & 0.16 & 2.39 & 0.018 \\
Model 2 & & & & & \\
Tipping System & 0.06 & 0.18 & 0.02 & 0.34 & 0.736 \\
Service Quality & 0.32 & 0.15 & 0.13 & 2.19 & 0.030 \\
Ability to Punish & -0.06 & 0.05 & -0.09 & -1.28 & 0.200 \\
Ability to Reward & 0.46 & 0.06 & 0.59 & 7.44 & 0.001 \\
Model 3 & & & & & \\
Tipping System & 0.09 & 0.16 & 0.04 & 0.55 & 0.583 \\
Service Quality & 0.20 & 0.13 & 0.08 & 1.60 & 0.112 \\
Ability to Punish & -0.03 & 0.05 & -0.05 & -0.73 & 0.467 \\
Ability to Reward & 0.17 & 0.06 & 0.21 & 2.60 & 0.010 \\
Negative Emotions & -0.07 & 0.04 & -0.10 & -1.52 & 0.130 \\
Positive Emotions & 0.48 & 0.07 & 0.52 & 7.26 & 0.001 \\
& & & & & \\
\hline & & & & & \\
\hline
\end{tabular}

Note. $N=200 . \mathrm{NV}=$ non-voluntary. Tipping system $(1=$ voluntary, $2=$ automatic $)$. Service Quality (1 = high, 2 = very high). 
Figure 1. Tipping system $\mathrm{x}$ service quality interaction on negative emotions and return intentions (study 1)
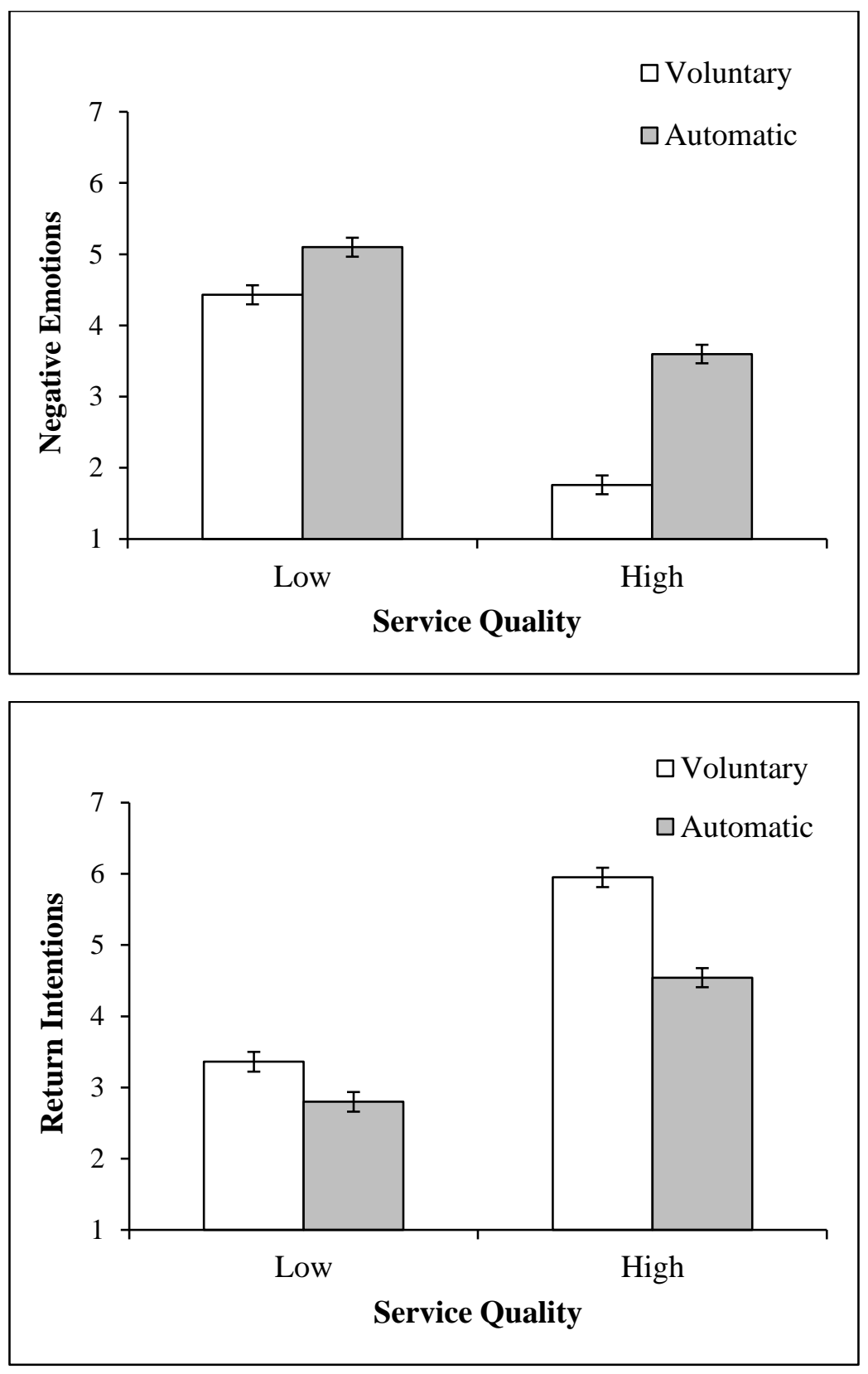

Note. Higher values correspond to higher negative emotions and return intentions. Error bars represent standard errors. 
Figure 2. Indirect effect of tipping system on return intentions via negative emotions (study 1)

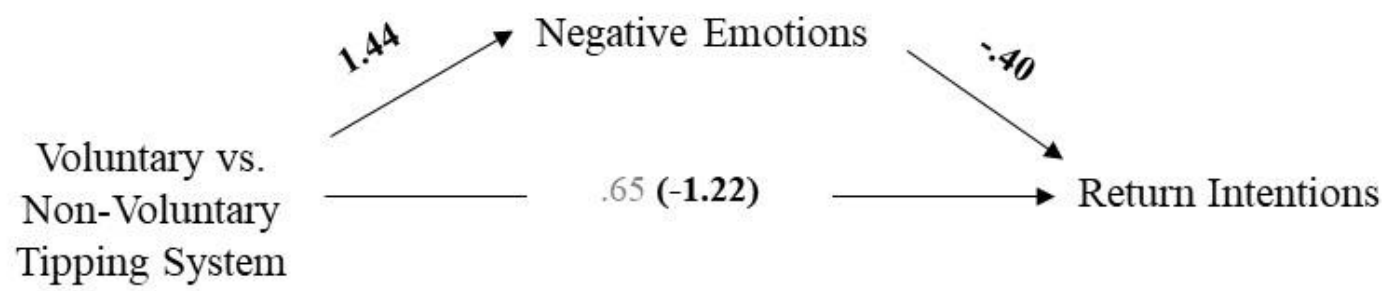

Note. $N=200$. Unstandardized coefficients shown. All bolded coefficients significant $(p<.01)$; gray coefficient significant $(p<.01)$. Service quality included as a covariate. Indirect effect significant $\left(\mathrm{CI}_{95}=-.8749,-.3255\right)$. Direct path from tipping system to return intentions shows partial (initial) coefficient after (before) controlling for negative emotions. 
Figure 3. Blocked vengeance vs. blocked gratitude models linking non-voluntary tipping systems with reduced return intentions

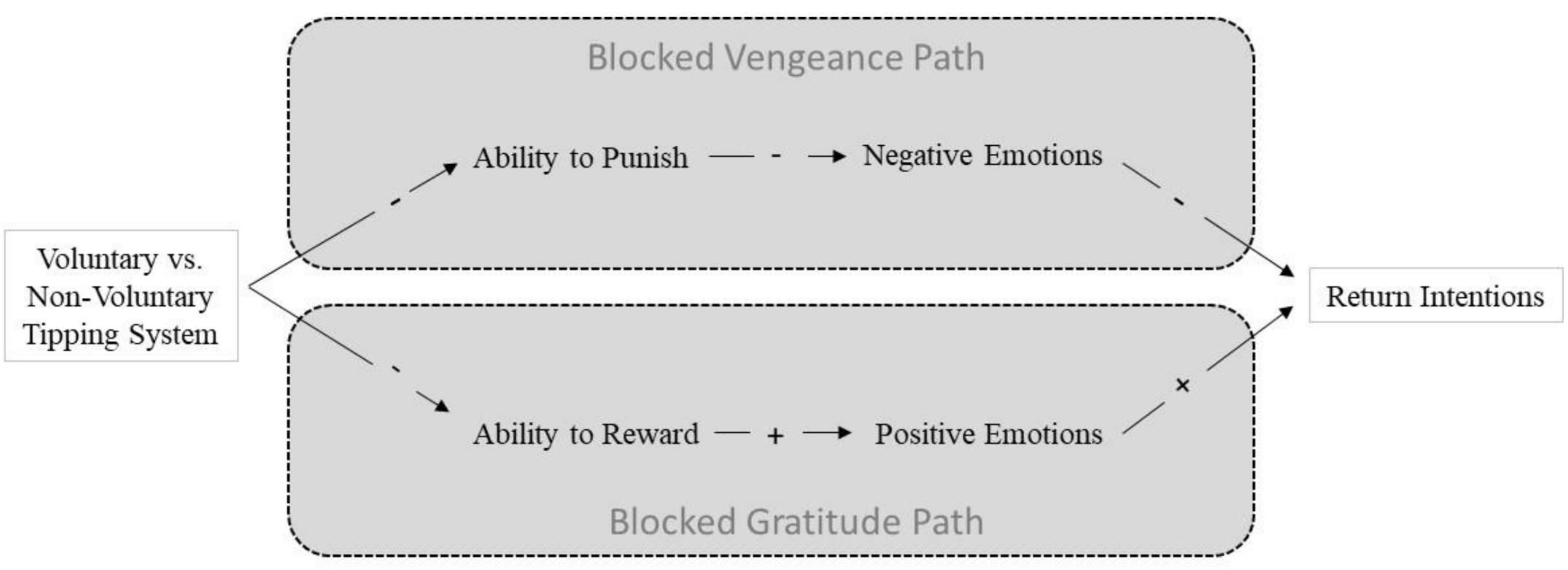


Figure 4. Blocked vengeance vs. blocked gratitude indirect effects tests (study 2)

\section{Blocked Vengeance Path}

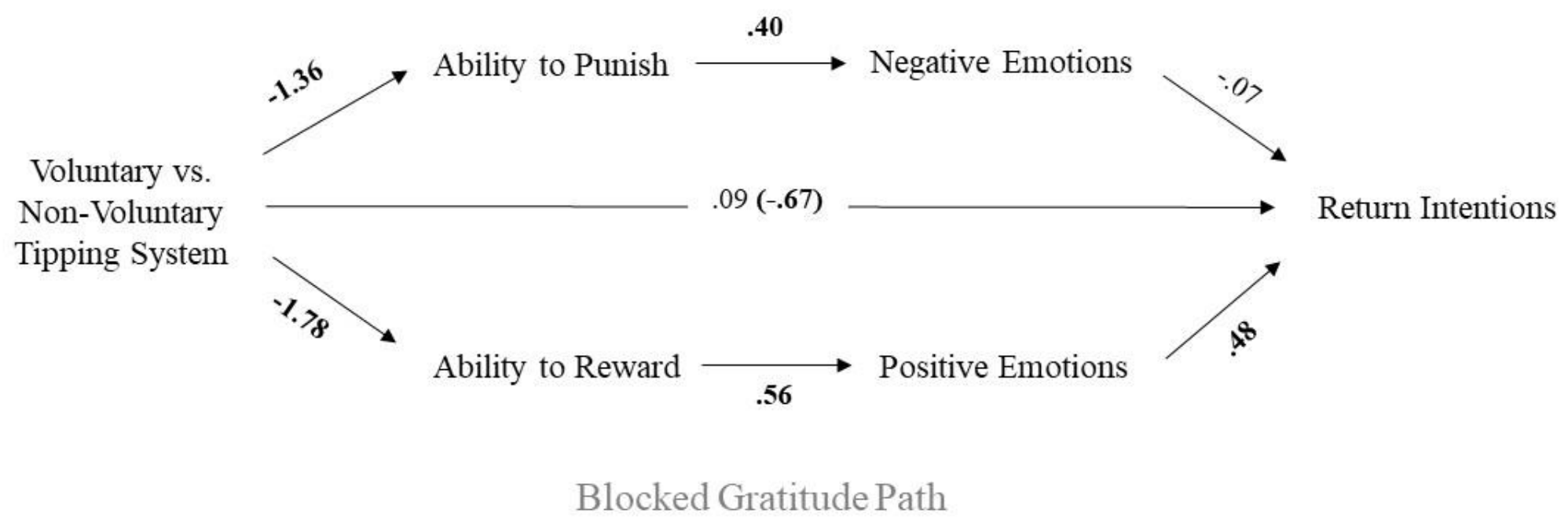

Note. $N=206$. Unstandardized coefficients shown. All bolded coefficients significant $(p<.001)$. Remaining coefficients not significant. Service quality included as a covariate. Blocked vengeance indirect effect not significant $\left(\mathrm{CI}_{95}=-.0121, .0856\right)$. Blocked gratitude indirect effect significant $\left(\mathrm{CI}_{95}=-.7738,-.2607\right)$. Direct path from tipping system to return intentions shows partial (initial) coefficient after (before) controlling for downstream model variables. 


\section{References}

Azar, O.H. (2004), “The history of tipping — from sixteenth-century England to United States in the 1910s", The Journal of Socio-Economics, Vol. 33 No. 6, pp. 745-764.

Azar, O.H. (2009), "Incentives and service quality in the restaurant industry: the tipping-service puzzle", Applied Economics, Vol. 41 No. 15, pp. 1917-1927.

Babin, B.J., Lee, Y.K., Kim, E.J. and Griffin, M. (2005), “Modeling consumer satisfaction and word-of-mouth: restaurant patronage in Korea”, Journal of Services Marketing, Vol. 19 No. 3, pp. 133-139.

Banik, S., Gao, Y. and Rabbanee, F.K. (2019), "Status demotion in hierarchical loyalty programs and its effects on switching: identifying mediators and moderators in the Chinese context", Journal of Business Research, Vol. 96, pp. 125-134.

Bechwati, N.N. and Morrin, M. (2003), “Outraged consumers: getting even at the expense of getting a good deal”, Journal of Consumer Psychology, Vol. 13 No. 4, pp. 440-453.

Berinsky, A.J., Huber, G.A. and Lenz, G.S. (2012), "Evaluating online labor markets for experimental research: Amazon.com's Mechanical Turk”, Political Analysis, Vol. 20 No. 3, pp. 351-368.

Bitner, M.J. (1990), "Evaluating service encounters: the effects of physical surroundings and employee responses”, Journal of Marketing, Vol. 54 No. 2, pp. 69-82.

Bitner, M.J. (1992), "Servicescapes: the impact of physical surroundings on customers and employees", Journal of Marketing, Vol. 56 No. 2, pp. 57-71.

Bitner, M.J., Booms, B.H. and Tetreault, M.S. (1990), “The service encounter: diagnosing favorable and unfavorable incidents", Journal of Marketing, Vol. 54 No. 1, pp. 71-84. 
Blodgett, J.G., Hill, D.J. and Tax, S.S. (1997), “The effects of distributive, procedural, and interactional justice on postcomplaint behavior", Journal of Retailing, Vol. 73 No. 2, pp. $185-210$.

Bougie, R., Pieters, R. and Zeelenberg, M. (2003), “Angry customers don't come back, they get back: the experience and behavioral implications of anger and dissatisfaction in services", Journal of the Academy of Marketing Science, Vol. 31 No. 4, pp. 377-393.

Boulding, W., Kalra, A., Staelin, R. and Zeithaml, V.A. (1993), “A dynamic process model of service quality: from expectations to behavioral intentions", Journal of Marketing Research, Vol. 30 No. 1, pp. 7-27.

Buhrmester, M., Kwang, T. and Gosling S.D. (2011), “Amazon’s Mechanical Turk: a new source of inexpensive, yet high-quality, data? Perspectives on Psychological Science, Vol. 6 No. 1, pp. 3-5.

Chang, C.C. (2006), "When service fails: the role of the salesperson and the customer", Psychology \& Marketing, Vol. 23 No. 3, pp. 203-224.

Chicago Tribune (2016), "No-tipping trend now at more restaurants, with mixed results", available at: https://www.chicagotribune.com/business/ct-no-tipping-restaurants-20160902story.html (accessed 4 March 2020).

Choi, S. and Mattila, A.S. (2008), "Perceived controllability and service expectations: influences on customer reactions following service failure", Journal of Business Research, Vol. 61 No. 1, pp. 24-30.

Deci, E.L. and Ryan, R.M. (2000), “The 'what' and 'why' of goal pursuits: human needs and the self-determination of behavior", Psychological Inquiry, Vol. 11 No. 4, pp. 227-268. 
Gagné, M. and Deci, E.L. (2005), "Self-determination theory and work motivation”, Journal of Organizational Behavior, Vol. 26 No. 4, pp. 331-362.

Galarza, D. (2017), "How some restaurants are bridging the pay gap between cooks and servers", available at: https://www.eater.com/2017/4/4/15160100/restaurant-tips-revenue-sharingstaff-labor-shortage (accessed 4 March 2020).

Goodwin, C. and Ross, I. (1992), “Consumer responses to service failures: influence of procedural and interactional fairness perceptions", Journal of Business Research, Vol. 25 No. 2, pp. 149-163.

Grace, D. and O'Cass, A. (2004), “Examining service experiences and post-consumption evaluations", Journal of Services Marketing, Vol. 18 No. 6, pp. 450-461.

Grégoire, Y. and Fisher, R.J. (2008), “Customer betrayal and retaliation: when your best customers become your worst enemies", Journal of the Academy of Marketing Science, Vol. 36 No. 2, pp. 247-261.

Hayes, A.F. (2018), Introduction to mediation, moderation, and conditional process analysis: a regression-based approach (2 $2^{\text {nd }}$ ed.), Guilford Press, New York.

Hui, M.K. and Bateson, J.E. (1991), "Perceived control and the effects of crowding and consumer choice on the service experience", Journal of Consumer Research, Vol. 18 No. 2 , pp. 174-184.

Joireman, J., Grégoire, Y., Devezer, B. and Tripp, T.M. (2013), "When do customers offer firms a 'second chance' following a double deviation? The impact of inferred firm motives on customer revenge and reconciliation”, Journal of Retailing, Vol. 89 No. 3, pp. 315-337. 
Kähr, A., Nyffenegger, B., Krohmer, H. and Hoyer, W.D. (2016), "When hostile consumers wreak havoc on your brand: the phenomenon of consumer brand sabotage", Journal of Marketing, Vol. 80 No. 3, pp. 25-41.

Karabas, I., Joireman, J. and Kim, S. (2019), "Why and when witnessing uncivil behavior leads observers to punish frontline employees and leave the firm", International Journal of Hospitality Management, Vol. 82, pp. 91-100.

Karabas, I., Orlowski, M. and Lefebvre, S. (2020), "What am I tipping you for? Customer response to tipping requests at limited-service restaurants", International Journal of Contemporary Hospitality Management, Vol. 32 No. 5, pp. 2007-2026.

Kees, J., Berry, C., Burton, S. and Sheehan, K. (2017), “An analysis of data quality: professional panels, student subject pools, and Amazon's Mechanical Turk", Journal of Advertising, Vol. 46 No.1, pp. 141-155.

Kim, Y.S. and Baker, M.A. (2019), “Observer reactions to other customer incivility: emotional labor, gratitude, loyalty to employee and tipping intention”, International Journal of Contemporary Hospitality Management, Vol. 31 No. 3, pp. 1292-1308.

Kwortnik Jr, R.J., Lynn, W.M. and Ross Jr, W.T. (2009), "Buyer monitoring: a means to insure personalized service”, Journal of Marketing Research, Vol. 46 No. 5, pp. 573-583.

Liu, X.Y., Chi, N.W. and Gremler, D.D. (2019), “Emotion cycles in services: emotional contagion and emotional labor effects", Journal of Service Research, Vol. 22 No. 3, pp. 285300.

Lynn, M. (2000), "National character and tipping customs: the needs for achievement, affiliation and power as predictors of the prevalence of tipping", International Journal of Hospitality Management, Vol. 19 No. 2, pp. 205-210. 
Lynn, M. (2009), "Individual differences in self-attributed motives for tipping: antecedents, consequences, and implications”, International Journal of Hospitality Management, Vol. 28 No. 3, pp. 432-438.

Lynn, M. (2016), "Motivations for tipping: how they differ across more and less frequently tipped services", Journal of Behavioral and Experimental Economics, Vol. 65, pp. 38-48.

Lynn, M. and Brewster, Z.W. (2018), “A within-restaurant analysis of changes in customer satisfaction following the introduction of service inclusive pricing or automatic service charges", International Journal of Hospitality Management, Vol. 70, pp. 9-15.

Lynn, M. and Kwortnik, R.J. (2015), “The effects of tipping policies on customer satisfaction: a test from the cruise industry", International Journal of Hospitality Management, Vol. 51, pp. 15-18.

Lynn, M. and Kwortnik, R.J. (2020), “Tipping policy effects on customer satisfaction: an informative failure to replicate", International Journal of Hospitality Management, Vol. 86.

Lynn, M. and McCall, M. (2000), "Gratitude and gratuity: a meta-analysis of research on the service-tipping relationship", The Journal of Socio-Economics, Vol. 29 No. 2, pp. 203-214.

Lynn, M. and Wang, S. (2013), "The indirect effects of tipping policies on patronage intentions through perceived expensiveness, fairness, and quality", Journal of Economic Psychology, Vol. 39, pp. 62-71.

Lynn, M. and Withiam, G. (2008), “Tipping and its alternatives: business considerations and directions for research", Journal of Services Marketing, Vol. 22 No. 4, pp. 328-336.

Lynn, M., Kwortnik Jr, R.J. and Sturman, M.C. (2011), "Voluntary tipping and the selective attraction and retention of service workers in the USA: an application of the ASA model", The International Journal of Human Resource Management, Vol. 22 No. 9, pp. 1887-1901. 
Lynn, M., Zinkhan, G.M. and Harris, J. (1993), “Consumer tipping: a cross-country study", Journal of Consumer Research, Vol. 20 No. 3, pp. 478-488.

Maxham, J.G. (2001), “Service recovery's influence on consumer satisfaction, positive word-ofmouth, and purchase intentions", Journal of Business Research, Vol. 54 No. 1, pp. 11-24.

Maxham, J.G. and Netemeyer, R.G. (2002), “A longitudinal study of complaining customers' evaluations of multiple service failures and recovery efforts", Journal of Marketing, Vol. 66 No. 4, pp. 57-71.

McColl-Kennedy, J.R., Patterson, P.G., Smith, A.K. and Brady, M.K. (2009), “Customer rage episodes: emotions, expressions and behaviors", Journal of Retailing, Vol. 85 No. 2, pp. 222237.

McColl-Kennedy, J.R., Sparks, B.A. and Nguyen, D.T. (2011), “Customer's angry voice: targeting employees or the organization?" Journal of Business Research, Vol. 64 No. 7, pp. 707-713.

McCollough, M.A., Berry, L.L. and Yadav, M.S. (2000), “An empirical investigation of customer satisfaction after service failure and recovery", Journal of Service Research, Vol. 3 No. 2, pp. 121-137.

McNiel, J.M., Lowman, J.C. and Fleeson, W. (2010), “The effect of state extraversion on four types of affect”, European Journal of Personality, Vol. 24 No. 1, pp. 18-35.

Min, H.K., Joireman, J. and Kim, H.J. (2019), “Understanding why anger predicts intention to complain among high but not low power customers: a test of competing models", Journal of Business Research, Vol. 95, pp. 93-102. 
Moskin, J. (2016), "Year of upheaval for restaurants that ended tipping”, available at:

https://www.nytimes.com/2016/12/13/dining/restaurants-no-tipping-service.html (accessed 4 March 2020).

Mulder, M.R. and Joireman, J. (2016), "Encouraging charitable donations via charity gift cards: a self-determination theoretical account", Journal of Nonprofit \& Public Sector Marketing, Vol. 28 No. 3, pp. 234-251.

Newton, J.D., Wong, J. and Casidy, R. (2018), "Deck the halls with boughs of holly to soften evaluations of service failure", Journal of Service Research, Vol. 21 No. 4, pp. 389-404.

Okan, M. and Elmadag, A.B. (2020), "Witnessing verbal aggression: role of customers' selfconscious emotions", Journal of Services Marketing, Vol. 34 No. 2, pp. 253-268.

Oliver, R. L. (1981), "Measurement and evaluation of satisfaction processes in retail settings", Journal of Retailing, Vol. 57 No. 3, pp. 25-48.

Paolacci, G. and Chandler, J. (2014), "Inside the Turk: understanding Mechanical Turk as a participant pool”, Current Directions in Psychological Science, Vol. 23 No. 3, pp. 184-188.

Parasuraman, A., Zeithaml, V.A. and Berry, L.L. (1985), “A conceptual model of service quality and its implications for future research", Journal of Marketing, Vol. 49 No. 4, pp. 41-50.

Richins, M.L. (1997), "Measuring emotions in the consumption experience”, Journal of Consumer Research, Vol. 24 No. 2, pp. 127-146.

Ryan, R.M. and Deci, E.L. (2000), "Self-determination theory and the facilitation of intrinsic motivation, social development, and well-being", American Psychologist, Vol. 55 No. 1, pp. 68.

Rychalski, A. and Hudson, S. (2017), “Asymmetric effects of customer emotions on satisfaction and loyalty in a utilitarian service context", Journal of Business Research, Vol. 71, pp. 84-91. 
Sheldon, K.M. and Hilpert, J.C. (2012), "The balanced measure of psychological needs (BMPN) scale: an alternative domain general measure of need satisfaction", Motivation and Emotion, Vol. 36 No. 4, pp. 439-451.

Smith, A.K., Bolton, R.N. and Wagner, J. (1999), "A model of customer satisfaction with service encounters involving failure and recovery", Journal of Marketing Research, Vol. 36 No. 3, pp. 356-372.

Star, N. (1988), The International Guide to Tipping, Berkley Books, New York, NY.

Sukhu, A., Choi, H., Bujisic, M. and Bilgihan, A. (2019), "Satisfaction and positive emotions: a comparison of the influence of hotel guests' beliefs and attitudes on their satisfaction and emotions", International Journal of Hospitality Management, Vol. 77, pp. 51-63.

Van Raaij, W.F. and Pruyn, A.T.H. (1998), "Customer control and evaluation of service validity and reliability”, Psychology \& Marketing, Vol. 15 No. 8, pp. 811-832.

Voorhees, C.M., Brady, M.K. and Horowitz, D.M. (2006), “A voice from the silent masses: an exploratory and comparative analysis of noncomplainers", Journal of the Academy of Marketing Science, Vol. 34 No. 4, pp. 514-527.

Voorhees, C.M., Fombelle, P.W., Gregoire, Y., Bone, S., Gustafsson, A., Sousa, R. and Walkowiak, T. (2017), "Service encounters, experiences and the customer journey: defining the field and a call to expand our lens", Journal of Business Research, Vol. 79, pp. 269-280.

Wan, L.C., Hui, M.K. and Wyer Jr, R.S. (2011), “The role of relationship norms in responses to service failures", Journal of Consumer Research, Vol. 38 No. 2, pp. 260-277.

Webb, D., Soutar, G.N., Mazzarol, T. and Saldaris, P. (2013), "Self-determination theory and consumer behavioural change: evidence from a household energy-saving behaviour study", Journal of Environmental Psychology, Vol. 35, pp. 59-66. 
Wee, H. (2016). "More restaurants opting for no-tip policies: survey”, available at:

http://www.cnbc.com/2016/06/02/more-restaurants-opting-for-no-tip-policies-survey.html (accessed 4 March 2020).

White, C. (2010), "The impact of emotions on service quality, satisfaction, and positive word-ofmouth intentions over time”, Journal of Marketing Management, Vol. 26 No. 5-6, pp. 381394.

Wildes, V.J., Mann, S. and Demicco, F. (1998), “The Penn Staie/USA Today Restaurant Service Survey or (un) Forkedible Frequencies”, Journal of International Hospitality, Leisure \& Tourism Management, Vol. 1 No. 3, pp. 103-115.

Williams, G.C., Grow, V.M., Freedman, Z.R., Ryan, R.M. and Deci, E.L. (1996), “Motivational predictors of weight loss and weight-loss maintenance", Journal of Personality and Social Psychology, Vol. 70 No. 1, pp. 115-126.

Wirtz, J., Orsingher, C., Chew, P. and Tambyah, S.K. (2013), “The role of metaperception on the effectiveness of referral reward programs", Journal of Service Research, Vol. 16 No. 1, pp. 82-98.

Xu, X., Liu, W. and Gursoy, D. (2019), "The impacts of service failure and recovery efforts on airline customers' emotions and satisfaction", Journal of Travel Research, Vol. 58 No. 6, pp. 1034-1051. 


\section{Appendix A}

Service quality and tipping system scenarios and experimental manipulations

Study 1

\section{Common Scenario}

The other day, you went to a restaurant to have dinner with a couple of your friends. After arriving at the restaurant and being seated at a table, the server brought you some water and the menus. After spending some time looking through the menu, the server returned to take your order. You ordered soup as a starter. Not long after, the server came back with everyone's orders and your soup.

\begin{tabular}{|c|c|}
\hline \multicolumn{2}{|c|}{ Service Quality Manipulation } \\
\hline Low Quality Service & High Quality Service \\
\hline $\begin{array}{l}\text { You started eating your soup and } \\
\text { immediately realized that it is not the soup } \\
\text { that you ordered. You asked your server } \\
\text { for a replacement. The server brought you } \\
\text { the correct soup, but it took a while and } \\
\text { the server treated you rudely. }\end{array}$ & You enjoyed your soup. \\
\hline \multicolumn{2}{|c|}{ Common Scenario } \\
\hline \multicolumn{2}{|c|}{ After everyone was done with their meal, the server brought everyone's checks. } \\
\hline \multicolumn{2}{|c|}{ Tipping System Manipulation } \\
\hline Voluntary Tipping & Automatic Gratuity \\
\hline $\begin{array}{l}\text { Once you received the check, you } \\
\text { browsed through the items listed and the } \\
\text { total price. You then inserted the amount } \\
\text { of tip that you wanted to give to the } \\
\text { server, signed the check, and left the } \\
\text { restaurant. }\end{array}$ & $\begin{array}{l}\text { Once you received the check, you } \\
\text { browsed through the items listed and the } \\
\text { total price. You then realized that a tip was } \\
\text { automatically added to the bill, as this } \\
\text { restaurant automatically adds tips to } \\
\text { account for the service charge. After } \\
\text { signing the check, you left the restaurant. }\end{array}$ \\
\hline
\end{tabular}

Note: Study 1 design: 2 (tipping system: voluntary vs. automatic) x 2 (service quality: low vs. high). 
Study 2

\section{Common Scenario}

The other day, you went to a restaurant to have dinner with a couple of your friends. After arriving at the restaurant and being seated at a table, the server brought you some water and the menus.

\section{Tipping System Manipulation}

(Before Commitment to Purchase)

\begin{tabular}{|l|l|}
\hline \multicolumn{1}{|c|}{ Voluntary Tipping } & \multicolumn{1}{c|}{ Automatic Gratuity } \\
\hline $\begin{array}{l}\text { As you were looking through the items on } \\
\text { the menu, you noticed the statement which } \\
\text { explained that customers decide how } \\
\text { much of a tip to give to the server. }\end{array}$ & $\begin{array}{l}\text { As you were looking through the items on } \\
\text { the menu, you noticed the statement which } \\
\text { explained that tips are automatically added } \\
\text { the bill to account for the service charge. }\end{array}$ \\
\hline
\end{tabular}

\section{Common Scenario}

After spending some time looking through the menu, the server returned to take your order. You ordered soup as a starter. Not long after, the server came back with everyone's orders and your soup.

\begin{tabular}{|l|l|}
\hline \multicolumn{2}{|c|}{ Service Quality Manipulation } \\
\hline \multicolumn{1}{|c|}{ High Quality Service } & \multicolumn{1}{c|}{ Very High Quality Service } \\
\hline You enjoyed your soup. & $\begin{array}{l}\text { You enjoyed your soup and thought the } \\
\text { overall service was excellent. }\end{array}$ \\
\hline
\end{tabular}

\section{Common Scenario}

After everyone was done with their meal, the server brought everyone's checks.

\section{Tipping System Manipulation}

(Each group matched with their previous tipping condition)

\begin{tabular}{|l|l|}
\hline \multicolumn{1}{|c|}{ Voluntary Tipping } & \multicolumn{1}{c|}{ Automatic Gratuity } \\
\hline $\begin{array}{l}\text { Once you received the check, you } \\
\text { browsed through the items listed and the } \\
\text { total price. You then inserted the amount } \\
\text { of tip you wanted to give to the server, } \\
\text { signed the check, and left the restaurant. }\end{array}$ & $\begin{array}{l}\text { Once you received the check, you } \\
\text { browsed through the items listed and the } \\
\text { total price. Since the tip was automatically } \\
\text { added to the bill, you just signed the check } \\
\text { and left the restaurant. }\end{array}$ \\
\hline
\end{tabular}

Note: Study 2 design: 2 (tipping system: voluntary vs. automatic) x 2 (service quality: high vs. very high). 


\section{Appendix B}

Measures across studies 1 and 2

Service quality evaluation (adapted from Grace and O'Cass, 2004)

Indicate the extent to which you agree or disagree with the following statements regarding the scenario you just read. $(1=$ strongly disagree, $7=$ strongly agree; study $1: \alpha=.97)$

a. The service here suited my needs. (study 1)

b. The service here is reliable. (study 1)

c. This establishment provided quality service. (studies 1 and 2)

Scenario realism (adapted from Wirtz et al., 2013)

Using the scale below, indicate the extent to which you agree or disagree with the following statement regarding the scenario you just read. $(1=$ strongly disagree, $7=$ strongly agree; study 1: $\alpha=.92$ )

a. It is easy to imagine being in the situation described in the scenario. (study 1)

b. Something like the situation in the scenario can happen. (study 1)

c. The scenario is realistic. (studies 1 and 2)

Perceived control (adapted from Mulder and Joireman, 2016; Sheldon and Hilbert, 2012)

Thinking about the tipping system in the scenario you just read, to what extent do you feel: $(1=$ strongly disagree, $7=$ strongly agree; study $1: \alpha=.73$; study $2: \alpha=.54$ )

a. that it is making you do things against your will [recoded] (studies 1 and 2)

b. you have control over how much you tip (studies 1 and 2)

Ability to reward (adapted from Lynn, 2016)

I believe the tipping system in the scenario I just read allows me to: $(1=$ strongly disagree, $7=$ strongly agree; study $2: \alpha=.80)$.

a. reward good service (study 2)

b. repay the server for his/her efforts (study 2)

Ability to punish (developed by the authors)

I believe the tipping system in the scenario I just read allows me to: $(1=$ strongly disagree, $7=$ strongly agree; study $2: \alpha=.93)$.

a. punish bad service (study 2)

b. "Get back at" a server who treats me badly (study 2) 
Positive emotions (adapted from McNiel et al., 2010)

Thinking about the situation in the scenario you just read, you feel: $(1=$ strongly disagree, $7=$ strongly agree; study $2: \alpha=.92)$
a. Happy (study 2)
b. Content (study 2)
c. Pleased (study 2)

Negative emotions (adapted from Bougie et al., 2003)

In the scenario I just read, I would feel: $(1=$ strongly disagree, $7=$ strongly agree; study $1: \alpha=$ .96 ; study $2: \alpha=.95)$
a. Outraged (study 1)
b. Frustrated (study 1)
c. Angry (studies 1 and 2)
d. Resentful (studies 1 and 2)
e. Annoyed (studies 1 and 2)

Return intentions (adapted from Boulding et al., 1993)

How likely is it that you would return to this establishment again in the future? $(1=$ not likely at all, 7 = very likely) (studies 1 and 2) 